Hegel and Kant

\title{
McDowell's Kant: Mind and World Graham Bird
}

McDowell's Mind and World is a commentary on a traditional, dualist, epistemology which puzzles over, and offers accounts of, a fundamental division between mental, subjective items, and non-mental, objective items ${ }^{1}$ in experience. The principal responses to that tradition which McDowell considers are those of Davidson's coherentism, Evans's form of realism, and Kant; but it is Kant's famous B75 text which occupies centre stage:

Gedanken ohne Inhalt sind leer; Anschauungen ohne Begriffe sind blind.

(Thoughts without content are empty; intuitions without concepts are blind).

I shall unfortunately say nothing of the philosophical import of McDowell's reflections on these positions, for my aim here is to focus on his account of Kant. My view is that his account is fundamentally mistaken, and I can indicate the points of disagreement in two related ways. First, as McDowell stresses, ${ }^{2}$ his Kant is Strawson's Kant. But, as I have argued elsewhere ${ }^{3}$ Strawson's Kant is not Kant, and so McDowell's Kant is not Kant either. Second, more specifically, Strawson's Kant has notoriously two sides, light and dark, insightful and monstrous, in which the dark side, the so-called 'Metaphysics of Transcendental Idealism", cannot be eliminated, and McDowell follows Strawson in this. Indeed in Strawson's The Bounds of Sense that dark side has equal status with the more promising insights, although more recently ${ }^{4}$ he has modified that strong view. My claim is that this bizarre dualism, and especially the dark side which McDowell unwisely calls the "transcendental story" (MW p 41), are not present in Kant in anything like the way that Strawson and McDowell suppose.

I shall concentrate, therefore, on supporting that claim against McDowell, but I shall also comment on a few more positive aspects of his account of Kant. For both Strawson and McDowell insist on a more positive, fruitful, side of Kant which they think it valuable to pursue. For McDowell indeed Kant "comes within a whisker" (MW p 42) of developing those insights, and he says (MW p 92), surely rightly, that the presence of the dark side in Kant should make us "marvel at the insight" which the more fruitful story represents. 5 I believe that the more positive story, as McDowell outlines it, is in some respects not Kant either, and that those misrepresentations point to weaknesses in McDowell's own philosophical position, but I shall not be able to pursue those claims here. In the first section I summarise McDowell's position both independently of, and in relation to, Kant; in the second I outline some central objections to his account; and in the third outline an alternative view of Kant which is strongly opposed to McDowell's traditionalist account. 


\section{A McDowell's General Framework}

McDowell's discussion responds to a traditional instability in epistemology between what is independently given to subjects and what is attributed to an objective world by those subjects. Evidently the simple 'subjective/objective' dichotomy is inadequate even to identify such instability. For both what is 'independently given to subjects' and 'what is attributed to an objective world by subjects' have objective and subjective features, as we might ordinarily understand those elusive terms. McDowell's title characterises this division simply in terms of mind, which for the tradition is 'subjective', and world, which for the tradition is 'objective', but he also contrasts a 'Myth of the Given" and subsequent responses to that myth. One such response, ascribed to Davidson, is a retreat to a 'coherentist', or idealist, position, which rejects a 'given' altogether; another, ascribed to Evans, is to cling to some independent given in the hope of avoiding both the original myth and the disadvantages of a Davidsonian retreat to coherentism. The problem for McDowell is to find some way of accommodating the natural motivations behind these, realist and idealist, positions while avoiding the persistent and unstable oscillation between them. Kant's B 75 epigram is to open the way to a resolution of that problem.

McDowell's way of meeting those requirements is to admit reference to a 'given', as a constraint on our beliefs, but to locate it within what he calls, following Sellars, 'the space of reasons'. The hope is that this will avoid both the Myth of the Given, and any retreat to coherentism by allowing some form of properly constituted constraint on our beliefs. In terms of the imagery of an unstable oscillation between extreme traditional positions, both Davidson and Evans are criticised for not having achieved an equilibrium position. Davidson, for example, is represented as one who rightly rejects the Myth of the Given but whose pendulum then swings too far on the opposite side in adopting a coherentist position. Evans is commended for recognising the dangers of the Myth, and for wishing to evade a Davidsonian position in response, but criticised for swinging too far back towards the Mythical extreme. Both Davidson and Evans are represented as adopting a position on either side of the equilibrium position, and so in danger of retaining the traditional oscillation even though with a more restricted swing. McDowell believes that equilibrium can be achieved through a proper integration of 'receptivity/sense' with 'spontaneity/understanding', a clarification of different forms of naturalism and Platonism, and his own conceptions of 'second nature' and 'Bildung'. I shall say little of those developments, except to note some weaknesses in the position which requires them.

\section{B McDowell's Appeal to Kant}

There are several points at which McDowell's framework echoes Kant's position. Quite obviously the wish to integrate sense and understanding echoes the B 75 text, but the imagery 
of oscillation is also borrowed from Kant (A ix-x). The swing which McDowell marks between the Mythical Given and an extreme coherentism matches Kant's explicit picture of an endless oscillation between dogmatism and scepticism, or between a Lockean realism and a Berkeleyan idealism. Kant's dissatisfaction with the tradition as he saw it at the end of the eighteenth century is essentially the same dissatisfaction which McDowell responds to in the twentieth; and that historical parallel is unsurprising. ${ }^{6}$ More generally McDowell consciously resists many traditional dualist assumptions including the exhaustive opposition between a Mythical realism and an unsatisfactory idealism; and it is plain that Kant is similarly motivated. ${ }^{7}$ Although there is room for argument about how far Kant's goals match the aspirations of the twentieth century, and although I shall later suggest that Kant is closer to them than McDowell admits, nevertheless there is a broad agreement here.

Disagreement arises in the additional picture which McDowell paints of the obligatory dark side of Kant's position

(MW p 41): But Kant also has a transcendental story, and in the transcendental perspective there does seem to be an isolable contribution from receptivity. In the transcendental perspective, receptivity figures as a susceptibility to the impact of a supersensible reality, a reality that is supposed to be independent of our conceptual activity in a stronger sense than any that fits the ordinary empirical world.

(MW p 42): Once the supersensible is in the picture, its radical independence of our thinking tends to present itself as no more than the independence any genuine reality must have. The empirical world's claim to independence comes to seem fraudulent by comparison. We are asked to suppose that the fundamental structure of the empirical world is somehow a product of subjectivity, in interaction with supersensible reality, which, as soon as it is in the picture, strikes us as the seat of true objectivity. But how can the empirical world be genuinely independent of us, if we are partly responsible for its fundamental structure?. It does not help to be told that it is only transcendentally speaking that the fundamental structure of the empirical world is of our making.

The same claims are repeated later:

(MW p 95-6)...if we take Kant's conception of experience out of the frame he puts it in, a story about a transcendental affection of receptivity by a supersensible reality, it becomes just what we need. Outside that frame, Kant's conception is a satisfactory way of avoiding our dilemma, the apparently forced choice between the Myth of the Given and a coherentism that renounces 
external constraints on our thinking. But the frame spoils the insight because the radical mind-independence of the supersensible comes to seem exemplary of what any genuine mind-independence would be, and then when Kant purports to attribute mind-independence to the ordinary empirical world... that looks merely disingenuous.

McDowell goes on to offer three explanations for Kant's grafting of this "profoundly unsatisfactory" (MW p 43) 'transcendental' story onto the insightful positive account. First McDowell suggests that Kant's wish to safeguard moral and religious beliefs has a part to play in his acceptance of the supersensible account. That motive, of course, finds its primary manifestation in the Third Antinomy construed as a decisive commitment to a world of supersensible reality. Of this explanation McDowell rightly comments that although it may account for the presence of the supersensible in the moral philosophy, it provides no motivation for such an appeal in the epistemological context. ${ }^{8}$ I indicate later how important is the division between the ways in which the concept of the supersensible is used in the epistemological and the moral contexts. Second he suggests that although Kant's position recovers the law-like character of nature against a Humean brute naturalism, it does not yet make room for the "Intelligibility of meaning" (MW p 97) or normativity. Consequently, the suggestion is, Kant is driven to accommodate these notions not in the natural, but in the supernatural, supersensible, realm. However, McDowell concedes in this case, too, that Kant's recovery of the law-like character of nature already involves some reference to the understanding and so to the 'intelligibility of meaning', so that this second explanation is not quite adequate either.

The third explanation, and the one on which McDowell must rest his case is simply that Kant lacked the apparatus of "second nature"

(MW p 97-8): Kant's lack of a pregnant notion of second nature explains why the right conception of experience cannot find a firm position in his thinking... ..we must simply marvel at his insight, especially in view of how the transcendental framework prevents the insight from taking proper form. And it is not that the transcendental framework is a gratuitous afterthought. In the absence of a pregnant notion of second nature, the insight can appear only in that distorted form.

McDowell's own pregnant conception of second nature perhaps needs more scrutiny in order to grasp the full force of this explanation, but his view covers at least these claims. First that Kant neither could, nor did, locate the needed 'intelligibility of meaning' in any natural sphere that he recognised, and was consequently forced to locate it in the supersensible. Second that there is no other way to locate that intelligibility without appealing to McDowell's 
conception of second nature. Such claims raise a number of questions. Of course the strength of such an explanation will depend crucially upon the prior belief that Kant was committed to the supersensible in the epistemology, for without that belief there would be nothing to explain. ${ }^{9}$ I shall suggest later that there is no good reason to suppose that he did, or had to, appeal to the realm of the supersensible in the way that McDowell claims. The further claim that only 'second nature' can meet the requirements remains unclear and I pursue it in only a limited way later.

These explanatory efforts are associated with a further point. McDowell thinks Kant was right to insist on a 'real', rather than merely a 'notional' connection between concepts and intuitions (MW p 98), but he also believes that it was this strong link which again inevitably drives Kant into the unsatisfactory 'transcendental' story. What seems to be the same point is expressed earlier (MW p 41) where McDowell says that we must not suppose that receptivity makes an even notionally separable contribution to its operation with spontaneity. In the later passage these points are also linked to an explanation of Kant's commitment to the supersensible.

(MW p 98): The real connection has to be that spontaneity is involved in the transcendental affection of receptivity by the supersensible. And now the good thought that our sensibility opens us up to a reality that is not external to the conceptual can show up only in a distorted form, as if the ordinary empirical world were constituted by appearances of a reality beyond.

It would be surprising if McDowell's account here did not focus on the central location for spontaneity, namely the self; and in fact he has an extensive discussion of that issue which follows Strawson's commentary on the Paralogisms and Deduction. I cannot deal with that aspect in all its detail, but $I$ want finally to tie in the account given so far with one aspect of McDowell's treatment of that issue. For McDowell goes on to admit that Kant at least begins to offer a satisfactory picture of the role of the self, and self consciousness, in relation to the salient aspects of our experience in the Deduction, but then adds one crucial proviso:

(MW p 99): Now it would be satisfying if the self that is in question here were, in the end at least the ordinary self. But it is hard to make that cohere with what Kant actually says.

Later this difficulty is spelled out:

(MW p 103): If Kant's connection between self-awareness and awareness of the world is to leave it open to us to regain the idea that the subjects of our experience are our ordinary selves, then the merely formal persistence of the 
' $I$ ', in the 'I think" that can "accompany all my representations", had better be only an abstraction from the ordinary substantial persistence of the living subject of experience. It had better not be something free-standing, which we might hope to build on in reconstructing the persistence of the ordinary self. But this does not seem to fit Kant's conception of what he is doing. Kant takes himself to be laying bare a necessary connection that is knowable a priori. And it would be hard to make the idea of an abstraction from the persistence of the ordinary self cohere with the temporal connotations he gives to 'a priori', as when he suggests that transcendental self-consciousness "precedes all data of intuitions" (A 107).

The same general message is apparent. Kant has some of the machinery to escape from the supersensible realm, to canvass relations which are immanent rather than transcendent, and so to anticipate a position close to McDowell's. But just as we saw earlier that Kant is supposed to be forced into the transcendent, supersensible, realm in accounting for the impact of an external reality upon our senses, so here, too, he is forced into a recognition that the central locus of experience, the self, cannot be, and cannot be properly associated with, anything other than a supersensible item. The self, to which Kant points, is a formal 'geometrical point', which can have no adequate relation to, and cannot be 'worked up into' (MW p.104), the substantial persistence of our ordinary empirical selves. Once again an idea which looks promising in McDowell's own terms becomes subverted into the dark, profoundly unsatisfactory, 'transcendental' story.

\section{II}

The central features of the dark story are familiar in the tradition, and the quotations from McDowell underline the following aspects:

1 'Receptivity figures as a susceptibility to the impact of a supersensible reality', that is, Kant is committed to a causal relation between noumena and our senses. That noumenal reality is to be independent of our conceptual capacity. (MW p 41)

2 'Once the supersensible is in the picture.. the empirical world's claim to independence comes to seem fraudulent" (MW p 42); "..the radical mind-independence of the supersensible comes to seem exemplary of what any genuine mind-independence would be" (MW p 95-6); that is, a priority is accorded to noumenal reality by comparison with which empirical reality is second class. 
"..the fundamental structure of the empirical world is somehow a product of subjectivity... But how can the empirical world be genuinely independent of us if we are partly responsible for its..structure?" (MW p 42); that is, we construct nature out of subjective mental states, representations or appearances. The second class status of that empirical reality is, then, reflected in its subjective character in contrast to the mind-independence of the supersensible. "... as if the ordinary empirical world were constituted by appearances of a reality beyond" (MW p 98 ).

It is not possible to demonstrate here the total failure of this traditionalist picture, though I believe that it is a total failure. What I shall do is first to make three general comments on inadequacies in McDowell's account, second to note three passages which firmly reject central parts of that picture, and third to consider one of the strongest motives which leads traditionalists to cling to this picture, namely the vocabulary of the Aesthetic. I restrict the argument, as McDowell does, to the context of epistemology, but it should not be inferred that I think commitment to the supersensible in Kant's moral philosophy is any more difficult to accommodate. And I am guided by the following strategy. Those traditionalists who canvass the dark story do not deny the existence of a more benign account running alongside it. It may be claimed, therefore, that to stress, as I shall initially, the good side of Kant's account is irrelevant to the issue of his also accepting the dark side. But, as I shall try to show, the good side is not merely an optional extra; it is at almost every point transparently at odds with the dark story. McDowell rightly marvels at the conjunction of such opposed theses, and my intention here is to strengthen that sense of wonder. In the light of the explicit conflicts in the three representative quotations it would, I think, be little short of a miracle if Kant really did run the two doctrines side by side. I shall finally ask what it is that ultimately motivates the retention of the dark story in the face of these powerful counter-indications. There are two kinds of answer to this question; one which deals with Kant's supposed acceptance of, and preference for, noumenal reality, ${ }^{10}$ and one which deals with the subjective impact of that reality as in (3) above. I shall focus on the second of these answers by considering the conclusions to the Aesthetic which use such terms as 'representation', 'appearance', 'subjective', and implicitly 'mind-dependent'.

\section{A Three Initial Weaknesses in McDowell's Account}

(a) McDowell's account of Kant's appeal to the supersensible should be qualified in several related ways. Kant never uses his term "libersinnlich" in either its adjectival or noun forms in the Critical philosophy before the second Critique. That should come as a surprise if, as McDowell thinks, Kant's appeal to such a realm is just as deeply embedded in the epistemology as in the moral philosophy. It also suggests that Kant recognises an important difference in any reference to the supersensible in the two contexts; and that is, of course, exactly what Kant says. ${ }^{11}$ That point shows, of course, not that Kant made no appeal to the 
supersensible in the epistemology, but only that, for whatever reason, he did not mark it there with that terminology; but it points also to a more substantial issue.

It is uncontroversial that Kant allows a conceptual reference to noumena quite generally. Such things are for us conceptually or logically, but not really, possible. In McDowell's terms we might say that the scope of the conceptual extends far beyond the sensory, for it is a well known part of Kant's diagnosis of Dialectical error that our concepts, essential as they are for empirical experience, carry with them the temptation to transcend it. McDowell understandably reports Kant's view in (1) above by claiming that the realm of noumena is independent of our conceptual capacities, but this conceals the fact that for Kant such a realm is wholly dependent on our concepts and the transcending temptations built into them. That leads to a more important objection. Concepts, especially a priori concepts on Kant's account, have a Janus-faced ambiguity; a good immanent side, responsible for our experience, and a dark transcendent side, responsible for Dialectical error. Now it is hard to understand how someone who has constructed such a diagnosis of fundamental philosophical error, and placed such weight upon it, should nevertheless also succumb so blatantly to the very same error. Whether he did or not, however, the picture shows that Kant has a three-fold rather than a dual classification of these operations. He distinguishes between an empirical, a transcendental, and a transcendent mode of operation, and thinks of his own philosophy as falling within neither the empirical nor the transcendent. ${ }^{12}$ McDowell not only draws no distinction between the transcendental and the transcendent, but also conflates them when he speaks of Kant's dark 'transcendental', instead of a 'transcendent', story. That conflation then allows no room for the three-fold distinction, and commits Kant to the dark story in a potentially question-begging way. McDowell says (MW p 42) that 'It does not help to be told that it is only transcendentally speaking that the fundamental structure of the empirical world is of our making", but that seems to be mainly because he disregards the significance of this apparatus and misdescribes it.

(b) Kant's interest in the immanent and transcendental, as opposed to either the empirical or the transcendent, modes of operation is associated with another piece of Kantian apparatus, namely the distinction between formal and material aspects of our experience. It is, again, uncontroversial that such a distinction plays an essential role in indicating the a priori, formal, rules which govern our experience in contrast to the a posteriori, material, realisation of those rules; and that this is connected with Kant's qualification of his form of idealism as 'formal' rather than 'material'. Material idealism is that traditional empirical idealism which rests its view on the basis of our empirical ideas, that is, mental sensations. These contrasts surface specifically in Kant's account of the character of transcendental enquiry (B 80-81), and of the distinction between appearances and noumena as one involving not separate orders of objects but separate conceptions of the same objects (B xviii, B xxvii, B 313-314). Recently that distinction has come to be labelled in terms of the contrast between a "two world" (material) 
and a "two aspect" (formal) account, but that terminology has created problems of its own ${ }^{13}$ and I prefer the 'formal/material' distinction. The direction in which these considerations point is decisively away from the traditionalist account that McDowell assumes. McDowell's account of the dark 'transcendental' story is essentially an empirical, psychological, material theory projected, however, onto a transcendent screen. It is an account committed to a material construction of Kant's project. The alternative story, which this apparatus indicates, has more in common with, and indeed to some extent anticipates, Carnap's distinction between the material and formal modes of speech. ${ }^{14}$ On that alternative account Kant, as he insists, is not making material empirical claims in psychology or projecting them onto a material transcendent screen.

(c) In his discussion of Kant's account of the self and self consciousness (MW p 103 above) McDowell considers, and immediately rejects on Kant's behalf, a route which would enable him to escape from the dark story as it applies to the self. If that account could be understood as an 'abstraction' from our ordinary experience it might, McDowell thinks, enable us to recover the idea that the "subjects of experience are our ordinary selves". The alternative is to regard Kant's formal 'geometrical point' of self consciousness as 'free standing', but then it would be impossible to 'build on this in reconstructing the persistence of the ordinary self'. McDowell offers two reasons for rejecting the 'abstraction' account; first that Kant expresses a "necessary connection knowable a priori" between self-awareness and awareness of the world, and second that the abstraction account does not "cohere with the temporal connotations (Kant) gives to 'a priori' as when he suggests that transcendental self consciousness 'precedes all data of intuitions' (A 107)". These points are not matters of trivial detail in McDowell's account. For as he makes clear later (MW p 111) it is precisely the supposed impossibility of recovering the idea of an ordinary self which marks Kant's lack of reference to 'second nature' and so prevents him from succeeding 'in his admirable aim to supersede traditional philosophy". 15 So even without a clear picture of what 'second nature' might be, if McDowell's assumptions here are faulty then Kant may succeed after all. I shall claim that McDowell's assumptions are indeed faulty.

It is worth recalling the standard procedure of abstraction which Kant deploys in identifying a priori aspects of experience. At B 5-6 he outlines just such a procedure and then follows it quite typically in innumerable passages where he wants to lay bare the underlying conditions for some ordinary experience. ${ }^{16}$ Explicit references to such a procedure in the Critique are so numerous that I list only a few such as A 116, A 119, B 144, B 162-3, A 355, A 398, B 341-2, and B 427-9. Several of these occur in the Deduction and most of them deal with Kant's transcendental account of the self. McDowell claims that that account of the self cannot nevertheless be an abstraction in line with this standard procedure because it involves a necessary connection knowable a priori. It seems natural to respond that it is precisely just such a priori connections which the abstraction procedure is intended to lay bare. Perhaps 
McDowell confuses Kant's use of abstraction as a philosophical method for identifying a priori connections with a Lockean account of abstraction as a learning procedure in which we acquire our concepts. He also claims that the abstraction procedure is in conflict with the temporal connotations of 'a priori'. Here it seems equally natural to respond by asking why it should be thought that Kant's account of a priority is temporal. The only reply McDowell offers is to advert to Kant's account of 'precedence' in the A 107 quotation. But that quotation clearly deploys the notion of precedence in the context of laying bare an underlying transcendental condition of our experience. Kant expresses the point earlier in the same passage:

What has necessarily to be represented as numerically identical cannot be thought as such through empirical data. To render such a transcendental presupposition valid, there must be a condition which precedes all experience, and which makes experience possible (A 107).

Here the same points are made in the non-temporal terminology of necessary connection, or underlying transcendental conditions. Kant's vocabulary here indicates again a claim about the formal conditions presupposed by some aspect of experience, and not a material reference to some supersensible item which chronologically precedes it. It would be entirely natural, therefore, to interpret 'precedes' here in that non-temporal way in which Kant characteristically identifies priorities among our representations in experience or prior conditions which make experience possible. ${ }^{17}$ That point is reinforced in the reference to $B$ 124-5 below where 'making possible' is a metaphysical condition rather than a causal and temporal preliminary in the psychological construction of experience. If there seems no reason to accept McDowell's arguments, it is nevertheless not difficult to understand why he appeals to them. It is because he accepts Kant's transcendental claims about conditions of experience as material, psychological, occurrently identifiable moments in that experience. For the same reason he thinks also that Kant fails because it would be impossible to 'build on' such a geometrical point in order to 'work up' or recover a reference to an ordinary, living, embodied subject of experience. As I shall suggest later this also runs counter to Kant's standard orientation. It paints a typically empiricist picture of the analytic construction of items of ordinary experience from the basic subjective data of our sensations, when Kant plainly is not canvassing any such empiricism or any such construction. It has become common to recognise that in the context of perception Kant is not a phenomenalist in that empiricist mould ${ }^{18}$ but it seems that his associated general rejection of any such empiricist construction has still not been understood. McDowell's further suggestion that Kant makes no room for a third person reference to the self, in line with his claim that Kant's account occurs exclusively "within the flow of consciousness" (MW p 101), is also not consistent with the passage at A 362 where Kant speaks of the outer observer as first representing a self in time. 


\section{B Three Representative Quotations}

(a) At B 124-5 Kant explains how he understands the claim that a representation might make possible an object.

There are only two possible ways in which synthetic representations and their objects can establish connection, obtain a necessary relation to and meet one another. Either the object alone must make the representation possible, or the representation alone must make the object possible. In the former case the relation is only empirical.... In the latter case the representation in itself does not produce the object insofar as its existence is concerned, for we are not here speaking of causality by means of the will. None the less the representation is a priori determinant of the object if it is the case that only through the representation is it possible to know the object.

This passage makes it clear that Kant's central transcendental task of identifying the conditions for experience, popularly expressed as the 'mind making nature' (MW p 42), is not empirical, causal, or psychological but modal and epistemic. How exactly that modal, epistemic, relation is to be formulated in current terms remains an open question, but there can be no doubt that Kant seeks to explain the necessity which belongs to his metaphysically prior conditions of experience. The popular conception of these conditions as a temporal and psychological process of construction is both ill-motivated and actually inhibits any such further enquiry.

(b) In Der Streit der Fakultaten Kant looks back on, and summarises part of, the achievement of the Critique. He says:

(Ak Vol 7, p 70): Then the Critique appeared and treated man in the world as a thoroughgoing active being. Man is himself the originator of all his ideas. and concepts, and ought to be the originator of his actions. This "is" and "ought" point to two different aspects of humanity... on one side sense and understanding, and on the other reason and free will. Everything is in nature: She has no "ought" in her vocabulary. But sense and understanding function only to determine what is and how it is, and consequently must themselves be characterised in nature, in this earthly world, and so belong to it.

This passage reveals two important points: First that Kant's role for the supersensible, however we understand it, draws the line noted earlier between the epistemic and the moral context, rather than one within the epistemic as McDowell claims. Still more important is that within the epistemic context references to our cognitive powers, to sense and understanding, are references to nature, to this earthly world, and not to any noumenal reality. I characterised 
McDowell's position as that of conceiving Kant's transcendental account as an empirical, material, causal, and psychological process projected onto a transcendent screen. The earlier quotation, (a) above, shows that that account is not empirical, material, psychological or causal; the (b) quotation shows that it is not projected onto any transcendent screen. It reinforces the replacement of the material account by a formal counterpart.

(c) In the Anthropologie Kant has a pointed comment about those who misunderstand his technical use for the term 'appearance'. He had, of course, attempted to clarify that use, and to avoid such misunderstandings, in the Critique (B 69-70). Now he says:

(Ak Vol7, p 142): I know myself only as appearance, not as a thing in itself ... I know myself in inner experience only as I appear to myself. This claim is often mischievously turned round to mean: It only appears to me that I have inner ideas and sensations, or that I exist.

In its colloquial use the term 'appearance' may be contrasted with, though not necessarily separated from, some accessible item which appears. That colloquial use is distorted in the traditional identification of appearances as subjective mental states such as sensations, and of the associated things which appear as separate items in an objective world. In Kant's technical, and transcendental, use the term is intended by contrast to guard us against the implication that its correlate, the thing in itself, is cognitively accessible to us in that way. It marks consequently a radical deviation from that traditional distortion. ${ }^{19}$ The same message is given in the Aesthetic.

(B 45): The transcendental concept of appearances in space ... is a critical reminder that nothing intuited in space is a thing in itself.

More importantly the passage also counts strongly against the attribution of a second class status to appearances for precisely the same reason. It indicates on the contrary that the reality of appearances has priority and that the supposed reality of noumena is an illusion. Such an allocation of priorities is quite at odds with McDowell's claims quoted above (MW $\mathrm{p} 42,95-6)$. In a more complex way the passage uncovers weaknesses in McDowell's understanding of Kant's perceptual vocabulary. It is simply wrong to talk of such terms as 'sensation', 'impression', 'intuition', and 'appearance' without marking firm distinctions between them, and especially to treat them all as names of mental states. ${ }^{20}$ If McDowell is less committed than this suggests that is, I think, primarily because of his reticence in explaining the vocabulary rather than because he draws the correct distinctions. In a similar way if it is understandable that Kant's term 'appearance' should seem to carry these traditionalist implications, we should not forget the effort Kant himself makes to avoid such 
misunderstandings. Perhaps he was unwise to use the term. The parallel term 'phenomenon' does not even seem to tempt these errors and might have been a better choice, even though Kant had a clear reason for distinguishing appearances from phenomena. ${ }^{21}$

These three passages explicitly repudiate central parts of McDowell's dark story, and cannot be said to be isolated or eccentric expressions of Kant's views. On the contrary I have chosen them because they capture in a clear and succinct way views which can be attributed to Kant on quite independent grounds. They form parts of a clear, central, core which nevertheless contrasts with the dark story and points in quite the opposite direction. I do not think that anyone who recognises this could seriously continue to ascribe that dark story to Kant without some major adjustment, but I recognise that traditionalists will attempt to evade those conclusions with the device noted earlier. They will say that these are simply more or less recondite aspects of Kant's good side which count not at all against the accompanying dark story. One way of answering such a defence is to insist, as I have done, on the transparency of the conflicts inherent in such a view; another would be to show further how deeply embedded in Kant's system is that opposition to the dark side. I want finally to offer an answer along those lines which outlines a very different overall picture of Kant's epistemological project, and which takes its start from the question: How, in the light of these counter-indications, is it possible to cling to McDowell's traditionalist view? Two kinds of answer might be given. One would be to catalogue the passages in which Kant appears to commit himself to the prior reality of noumena, and then to show that such a commitment is either unnecessary or erroneous. ${ }^{22}$ I cannot attempt that here, though I have considered it elsewhere. Another kind of answer, which I can attempt, is to locate and re-interpret some central passage which is widely thought to commit Kant to the dark story. Since I believe that the vocabulary and conclusions of the Aesthetic provide the single most powerful motivation to cling to the traditional view, I shall examine those aspects and use them to offer an overall picture of Kant's project which is totally opposed to the tradition.

There is, of course, no doubt that Kant makes claims in the Aesthetic which seem to commit him to the dark story. For the most part in that section the commitment is to the 'subjective' side of that story; that is, it appears to locate space, time, and appearances within the traditional subjective realm of mental states or representations. He says that space and time are 'forms of intuition', 'subjective conditions of sensibility', 'nothing apart from our representations', which 'exist in the mind a priori', and are 'in us'; that is, they are 'minddependent'. If these claims are interpreted within the tradition, which assumes a basic and exhaustive division between the mental and the physical and gives an epistemic piority to the former, then it will seem natural to treat them as a clear commitment to a standard form of idealism, perhaps indeed to a crude Berkeleyan form. Once that is accepted, it will seem just 
as natural to commit Kant to the other side of the dark story, that is, to the existence of noumena as a hopeless way of attempting to recover an empirical reality, or confirming his

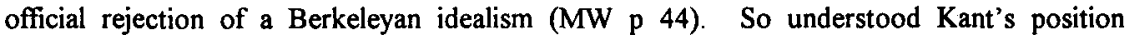
becomes transparently untenable. It would inherit the worst forms of rationalist realism, a form of McDowell's 'rampant Platonism', coupled with the most extreme form of empiricist idealism. And then all the subsequent efforts at B 43-46, B 51-53, and in the 'General Observations" (B 59ff), to elucidate that position, to distinguish it from Locke's or Berkeley's, and so to make it tenable, can be set aside as merely confused

Since I want to claim that such an account gets off on the wrong foot in treating those Kantian claims as a commitment to a traditional idealism, it would be question-begging simply to assume that they must be so interpreted. What is needed is to show that there are alternative ways of understanding those claims, and that Kant pursues them. But once we set aside the question-begging assumption it is not difficult to see both that there are such alternatives, and that Kant canvasses them in an attempt to reject the traditionalist picture. What is more difficult, and what still remains to be done, is to complete the project which Kant maps out in this way.

That the Kantian claims should not be assumed to commit him to a traditional idealism can be easily seen, for terms such as 'subjective' or 'mind-dependent' are notoriously ambiguous. The relation of 'dependence' involved here needs more clarification as McDowell himself implies, when he distinguishes, but does not elucidate, a 'radical' and a 'genuine' mind-independence (MW p 96). That distinction still echoes the basic dualism of the tradition, but I want to cast the net wider. If, for example, I canvass the plausible view that such a concept as 'checkmate' cannot be grasped independently of chess playing experience, or is in some way dependent on that experience, it will be obvious that such a claim is unclear. But in some ways in which it can be made plausible it cannot be naturally fitted into the traditional dualism of subjective mind and objective world. Nobody would think of inferring from such a claim that checkmates are just mental sensations like pains. Nor is it obligatory to construe such a claim as confined to private experiences. Chess playing is a public phenomenon, and checkmates are publicly accessible parts of it. The experience of chess playing is something shareable by human beings in general. Even if in this case such an experience owes something to human invention, which may make it 'mind-dependent' in some further way, that still does not make 'checkmate' the name of a private subjective sensation.

More subtle consequences can be extracted from the example. In those ways of making the claim plausible it does not have to be either semantic or reductive. It would be absurd to suppose that we can 'build up' the whole game of chess on the basis of such private experiences as a sensation of checkmate; on the contrary any such private experiences derive their content in part from the larger scale public character of the game. Nor is it obvious that the dependence relation which holds between that concept and the game as a whole is simply semantic. Standard empiricist semantic accounts rely on a reduction from larger to smaller 
scale phenomena and follow a typically verificationist path, such as that from public phenomena to private sensation, but this dependence relation follows the opposite direction. It would be possible, in line with some recent philosophical views, to regard a dependence of our representation of checkmate on the game of chess as semantic so long as one accepts some form of semantic holism. ${ }^{23}$ But this requires a clearer picture of what we understand by 'semantic', is not obviously viable, and certainly is at odds with the traditional empiricist approach. We do not have to, and may not wish to, treat such a relation as semantic at all.

Such an example demonstrates the considerable scope for interpreting such terms as 'subjective' or 'mind-dependent' outside the tradition. It shows that we may construe such dependence relations not as atomist, reductive, or semantic but as holist and metaphysical. It may be said that this example has no bearing on philosophical issues, but there are two good reasons to reject that claim. For first the same points arise even for more philosophically salient claims about, say, colours and pains, which McDowell discusses; and second it is clear that Kant's own interests march precisely along these anti-traditional lines.

For the same argument would show that even if we think of both colours and pains as graspable only within the scope of a typically human experience, this would establish neither that they were both mental subjective sensations, nor that we could make no discrimination between them. We may have independent grounds for classing pains, rather indiscriminately, as mental sensations, but we may also have independent grounds for thinking of colours quite differently. Once again while there is some unclarity about how exactly we should construe, or formulate, such a dependence it seems that there are ways of construing it which do not entail those traditionalist conclusions. In a similar way that dependence, in the cases of colour and pain, may be understood as neither atomist nor reductive nor semantic. It may simply map the relation which exists between those and other representations within the scope of human experience and be called 'metaphysical' and 'holist' rather than 'atomist' or 'semantic'. Such a project of providing a map or inventory of experience, and of our representations within it, can be called 'descriptive', and associated both with Kant, and with Strawson's 'descriptive metaphysics'.

If these accounts gesture towards an understandable project opposed to the tradition, the question still remains whether it echoes Kant's position. It seems to me that there are decisive grounds for answering affirmatively. I note at the start, however, that if this is so, then Kant is occupying a position almost directly opposite that of the tradition in which McDowell's dark 'transcendental' story is embedded That should not be at all surprising, given that such an opposition to the tradition is exactly what Kant himself expresses, as McDowell rightly acknowledges (MW p 111). More specifically and summarily $I$ add the following points in support of my claim.

i) Kant's project is that of constructing a descriptive 'inventory' of our experience (A $\mathrm{xx}$ ), and this goes naturally with the idea of mapping relations between our representations 
within experience. To map those relations, in uncovering the conditions which make aspects of our experience possible, is to record those dependence relations which hold between items in our experience. Its primary interest in mapping the a priori relations which form the governing rules of that experience goes with a holist rather than atomist standpoint, but that too should not be surprising given that Kant rejects empiricism. That empiricist atomism, with its analytic construction, typically goes with a verificationist account of meaning which Kant is now widely understood to have rejected In a similar way one specific form of such a programme, namely phenomenalism, is also now generally and rightly not attributed to Kant. ${ }^{25}$ The alternative descriptive inventorial account goes also against a standard traditionalism whose central task is to seek a philosophical justification for knowledge against scepticism. That does not mean that Kant has no interest in scepticism, but only that his response to it, on the basis of his inventory, is left open; it does not have to be restricted to the exclusive alternatives canvassed in the dualist tradition. We might conjecture that his response is to say that the inventory, with its dependence relations, shows that sceptics have misdescribed our experience. $^{26}$

ii) The descriptive inventorial project is further elaborated in Kant's "Amphiboly" section (B 316-349), for there he envisages the task of transcendental reflection, that is of correctly 'locating' or mapping ${ }^{27}$ our representations in relation to each other (B 316-318). It is entirely natural to express this, as I have just done, by speaking of the relations between 'our representations' and to speak in this way of the construction of the map of experience, without any commitment to those representations being themselves private mental states assimilated to basic sensations like pain. There are two connected elements here that need exposure. First our experience can be identified only in terms of our representations; our experience is as we take it, that is, as we represent it. It cannot be grasped or identified apart from those representations. The terminology of representation thus goes naturally and inevitably with Kant's project but has no need to adopt the traditional opposition between subjective mental state and represented world. Second to speak of 'our' representations or of 'our' experience reinforces that point, for what it precisely confirms is that we are talking about a general human experience and not that private set of sensations which belong to each individual. Strawson (BS p 197, also 193-4 and 256) complains that Kant's appeal to the first person plural is unjustified; but that is only because he attributes to Kant the very traditional dualism which Kant rejected. The complaint would be justified if Kant were firmly locked into the traditional dualist position, with empirical ideas or sensations at its base, and if his use of these expressions 'our representation' and 'our experience' followed that position. But Kant is not, like empiricists, starting with each individual's purely private atomist sensations and seeking to 'build up' or justify from there our developed communal experience on phenomenalist lines. It is that very communal, developed, experience of humankind which his inventorial project seeks to map, and that developed experience which provides the data for the abstraction 
procedure which uncovers the dependence relations between items in it. That is why McDowell's failure to understand Kant's use of abstraction in his project, and his resulting ascription of an empiricist construction programme to Kant, are so damaging and so wide of the mark.

This throws light on Kant's claim at B 42-3, immediately after the passages in the Aesthetic account of space which seem to commit him so strongly to the dualist imagery:

It is, therefore, solely from the human standpoint that we can speak of space..If we depart from the subjective condition under which alone we can have outer intuition....the representation of space stands for nothing whatever.

For the reference to the 'human standpoint' can now be understood not as a commitment to the traditional dualism of subjective representation and objective world, but to that developed human experience and the project of mapping it. The passage shows too how we can understand in a non-traditional way the claim that space and time are nothing apart from our representations (eg B 44). For it can be understood to claim not that space and time are constructed from our sensations, nor that they belong to the category of sensations, both of which Kant in any case explicitly denies, but that they have a role only within the scope of our human experience. The passage shows that space and time are not, to use Susan Haack's categories, strongly but only weakly mind-dependent. ${ }^{28}$ In line with the project of transcendental reflection in the Amphiboly Kant's conclusions should be expressed by saying that space and time are intuitive and a priori rather than that they are intuitions and innate. In this way the apparently committed set of claims can now be seen to point in a very different direction, not towards the tradition but firmly away from it. Kant's account of experience is anthropocentric, but not traditionally idealist.

iii) It may be objected that even if such a reading is possible we have few grounds to ascribe it to Kant other than charity. That this is not so should already be clear. Kant's text signals that direction away from the tradition quite clearly; it is only an assumed dualist and traditional commitment which has prevented some commentators from acknowledging it. But I add one further point about Kant's use of 'representation' in this context. Again immediately after those apparently committed passages in the Aesthetic, both in the section on space and in that on time, Kant seeks to elucidate what his claims amount to. Those qualifications, including the clarification of his term 'appearance', but above all his acceptance of an empirical reality and rejection of a transcendent reality, reinforce the same points. That Kant has a fourfold distinction between empirical and transcendental realism and idealism is evidently itself a rejection of the simpler traditional dualism of subjective ideas and worldly objects. The passages which seem to canvass that traditional dualism come immediately before that more complex scheme and should be understood in the light of it. For a significant part of those 
qualifications is a rejection of empirical idealism coupled with transcendental realism, which represents a standard traditional dualism between mind and world, private sensation and public object. So the rejection of empirical idealism is a rejection of that subjective side of the traditional story, that is, a rejection of the belief that all our knowledge and experience has to be based on, built up out of, and justified in terms of, that private, individual, atomist sense experience.

It is quite clear in any case that Kant's term 'representation', like his term 'appearance', has to be understood in a special transcendental way, and some indication of that technical use has been exploited already in (ii). Just as Kant explicitly distinguishes between two senses of the term "buter object", the empirically real spatial phenomenon and the transcendent noumenon (A 369-370), and so points to a strong and a weak sense for 'mind-independence', so his position commits him to a parallel distinction for the term 'representation' and for the term 'mind-dependence'. We have seen already that to talk of our representations in experience is not to talk of each individuals' private atomic sense experiences, or to envisage a typical empiricist construction from them of the outer world. To map dependence relations in our experience just is to map those relations which hold between the representations which constitute that experience; there is nothing else to record. But that does not mean that we cannot make discriminations within that experience between, for example, mental states properly so called and empirically outer independent objects. On the contrary that is one central function which such a map should perform, as Kant indicates in the footnote to B xl. Now it is clear that a distinction between a weak and strong sense for 'mindindependence' entails a corresponding distinction between weak and strong senses of 'minddependence'. ${ }^{29}$ Kant does not officially mark that ambiguity, as he does that of 'outer object', but his view is committed to it, and the distinction he draws between 'empirical idealism' and 'transcendental idealism' marks it. It draws a distinction between the traditional task of identifying empirical ideas, that is private sensations, out of which our public experience is to be constructed, and the descriptive task of mapping relations between the items which constitute our experience. It marks a distinction not crudely dualist between what is minddependent and what is mind-independent, but, like Susan Haack's account, between strong and weak forms of 'mind-(in)dependence'. It is, to echo a point made earlier, to mark not a material distinction between two sub-species of private sensations, 'ideas' in that committed empirical sense, but a formal distinction between two ways of looking at our experience and two ways of understanding what a representation is. The former, traditional, way is atomist and dualist; the latter, Kant's way, is neither.

\section{IV}

The picture presented above is firmly anti-traditional. It deviates from the tradition at almost every point and so from traditionalist accounts of Kant such as McDowell's. It may be 
thought by some to be too unfamiliar, too novel, to be taken seriously, even though such an account has been canvassed before and most current commentators now accept separate parts of it. The phenomenalism, the verificationism, the empiricism, and the complaints about transcendental psychology have now all been separately rejected. What is perhaps unfamiliar is the package which brings these parts together in a consistent whole. And yet such a package is the natural way of resolving the issues which arise from those separate elements. One of the benefits of such an alternative account is just that it offers a final resolution for the central mystery in Kant, which I take to be his commitment to noumena and consequently his understanding of such terms as 'appearance' and 'representation'. The traditionalist dualism which ascribes unqualified the dark transcendent story to Kant cannot resolve that mystery. It would, however, be wrong to recommend that alternative account solely for that reason. I put it forward, on the contrary, as firmly based on Kant's own text; indeed as more firmly based on that text than the traditionalist account it replaces. It is true that the connections with the text, and with Kant's own way of explaining his position, require a more careful scrutiny than is common. But if the traditionalist account rests on a less careful attention to Kant's own text then it seems to me that that is another good reason for at least querying, and in the end rejecting, that traditionalist view.

Graham Bird

University of Manchester

1 This is the most general, and crudest, way of drawing such a distinction. It is, of course, not just the ordinary contrast between what is mental and what is physical, but a philosophical gloss on that distinction, and it should not be thought that I accept its terms. McDowell himself invokes also related, but different, distinctions between the natural and the intentional, and the natural and the normative, in order to canvass more subtle contrasts.

2 MW p viii. McDowell actually says: 'I am not sure that Strawson's Kant is really Kant ..", but I think his reservations echo the belief that what Strawson approves in Kant is not adequately expressed by Kant, while my claim is that what Strawson disapproves in Kant is not present in Kant's text.

3 See my 'Recent Interpretations of the Transcendental Deduction", Kant-Studien 1974, Akten des 4-ten Kant-Kongresses, Teil I pp 1-14.; "Kant's Transcendental Idealism" in Idealism - Past and Present ed G Vesey, CUP, 1982; and "Tradition and Revolution in Kant", forthcoming in Kant-Studien.

4 In "The Problem of Realism and the A Priori", in P Parrini (ed), Kant and Contemporary Epistemology, Kluwer, Dordrecht, 1994.

5 It is difficult to overestimate the marvel. Later I suggest that it is so striking as to count against the attibution of the dark story to Kant.

6 In Kant's Theory of Knowledge, Routledge, 1962, Preface p ix, I had also indicated that historical parallel.

7 Kants revolutionary aspirations and his Copernican experiment indicate generally a rejection of traditional dualisms, but that motivation is evident also throughout the Dialectic. Even the distinction between sense and understanding, as McDowell rightly 
sees, is not a rigid dualist separation, as I had also indicated in Kant's Theory of Knowledge pp 58ff.

8 Later I indicate how important is the distinction between the epistemological and moral contexts in understanding Kant's appeal to the supersensible. McDowell's case, however, rests solely on the former epistemological context and I restrict my own comments to that.

9 It is important to separate the attractiveness of the diagnosis for some putative error from the establishment of the error itself. Bennett's ingenious diagnosis of Kant's alleged error in canvassing the synthetic a priori classification presupposed, and did not establish, that there was any error. Kant's Analytic, Cambridge, 1966, pp 6-8, 39-44).

10 I have considered that former issue about Kant's commitment to noumenal reality elsewhere in Kant's Theory of Knowledge Ch 2, 'Kant's Transcendental Idealism" and "Tradition and Revolution in Kant".

11 B xix-xxiii, the Preface to the Second Critique and the Introduction to the Third.

12 For example B 8-10; B 737-742. The explicit distinction between the transcendental and the transcendent is made at $B$ 352:

13 Richard Aquila "Things in Themselves and Appearances: Intentionality and Reality in Kant", Archiv fur Geschichte der Philosophie 61 (1979) pp 293-308. Hoke Robinson, "Two Perspectives on Kant's Appearances and Things in Themselves", Journal of the History of Philosophy Vol XXXII, July 1994.

14 R Carnap, Logical Syntax of Language Kegan Paul, London, 1937. Carnap's account is more technical than Kant's, but has also evident weaknesses. One is his insistence that formal and material sentences are equivalent, or equipollent, even though for 'quasi-syntactical' or 'pseudo-object' sentences the material mode of expression is misleading. Another arises from some unplausible analyses, as when he claims that "Yesterday's lecture was about Babylon" is equivalent to 'In yesterday's lecture either the word 'Babylon' or a synonym occurred". Kant's account is less formally developed, and rests on a recognition of an intentionality which enables us to speak of apparent objects under different descriptions and without commitment to existence, and of philosophical theories as providing such re-descriptions of familiar objects in experience.

15 McDowell's correct acknowledgment of Kant's aim to supersede traditional philosophy enables me to express my disagreement with him in a sharper way. Since for McDowell Kant's failure rests on his acceptance of the dark story, and since I deny that Kant accepted that story, it is open to me to claim that Kant was more successful in his aim than McDowell allows. This has implications for the more positive project that Kant pursues, but I cannot deal with them here.

16 See also, for the moral context, the way in which Kant outlines his procedure in the Grundlegung. But that procedure is standard throughout the Critical philosophy.

17 Most commentators on Kant nowadays do not think that Kant's priorities should be understood in any such temporal way. A recent example of that general view is Susan Neiman in The Unity of Reason, OUP 1994, p 50.

18 On Kant's rejection of phenomenalism see Kant's Theory of Knowledge Ch 1, and 'Kant's Transcendental Idealism'. McDowell complains of Allison that he wrongly ascribes a 'psychologistic phenomenalism' to Strawson's account of Kant, but there is no doubt that Strawson does, wrongly, ascribe a 'phenomenalistic idealism' to Kant throughout Part V of The Bounds of Sense.

19 J L Austin, Sense and Sensibilia, OUP 1956 makes these points in comparing the philosophical sense-datum tradition with our colloquial use of such terms as 'appear'. It has sometimes been thought that Austin's interest in the minutiae of ordinary 
language had no relevance to the philosophy of perception (See J Bennett, Mind Vol LXXV, 1966, pp 501-515) but this under-rates Austin's achievement in that work. Bennett wrote: "What has this to do with the old questions about appearance and reality ? Almost nothing.", and referred to these old questions as "the great tradition of modern epistemology", op cit p 513. But Austin, like Rorty much later, was precisely aiming to reject that 'great tradition'. Both Kant and Austin understood how damaging unmarked philosophical distortions of colloquial use could be. See my entry 'g L Austin" in A Companion to Epistemology ed by J Dancy and E Sosa, Blackwell, 1992, pp 34-36.

20 The terminology is too complex to be considered here in detail. But sensations, or sometimes 'impressions', are clearly mental states with an a posteriori content; intuitions have a direct relation to represented objects and can have a priori content; while appearances are the, indeterminate, objects of empirical intuitions. Sensations can be assimilated to crude 'subjective' mental states, but neither 'intuition' nor 'appearance' can be understood in that simple way. Kant invokes something like an 'intentional' account of the content of intuitions as a way of underlining the immediate relation he claims between those representations and the objects represented Although the notions of 'intentionality' and 'externalism' are both unclear, and associated with later philosophers, nevertheless Kant's views can be associated with those ideas. I discussed these issues extensively in Kant's Theory of Knowledge eg pp 6, 15-16, 35 , $54 \mathrm{ff}, 63,78$.

21 See Kant's Theory of Knowledge pp 47ff. for a discussion of Kant's efforts and their relation to the distinction between primary and secondary qualities. Of course Kant wished to distinguish 'appearance' and 'phenomenon' (see Kant's Theory of Knowledge pp 53-54) by associating the former strictly with the senses and the latter with the understanding's grasp of what appears to the senses. Kant's way of drawing this distinction has more in common with the view of Evans's 'informational system', which McDowell criticises, than with McDowell's own position (MW pp 47-65).

22 Erich Adickes provided an exhaustive catalogue of Kant's apparent commitments to noumena in the Critique in his Kant und das Ding an Sich I considered, and rejected, some of those commitments in Kant's Theory of Knowledge and 'Tradition and Revolution in Kant". As a result of examining Adickes's catalogue in detail before 1962 I came to the view that his conclusions were unjustified. I hope to publish the results of that survey.

23 Quine's form of semantic holism has been influential, and Wittgenstein's later philosophy can be read as a gesture towards some form of holistic view of language. But these notions remain obscure and sometimes controversial. See, for example, Fodor, Psycho-Semantics MIT Press, 1987; Andy Clark, Microcognition MIT Press, 1989; and Fodor and Lepore, Holism; A Shopper's Guide, Blackwell, 1991.

24 The idea of providing a descriptive map of experience is not confined to Strawson, although he coined the term 'descriptive metaphysics'. Some version of such a project is present also in Ryle's philosophy and in Quine's. Kant's version differs importantly from Strawson's in a number of ways. It relies on a synthetic a priori classification which Strawson rejects; it is opposed to a 'justificatory' rather than a 'revisionary' metaphysics; and it produces a different response to scepticism.

$25 \quad$ Kant's Theory of Knowledge Ch 1.

26 See my 'Kant's Transcendental Arguments" in Reading Kant ed E Schaper and W Vossenkuhl, Blackwell, 1989, pp 21-39.

27 Kant also uses the 'map' imagery, and even speaks of Hume as 'one of the great geographers of human reason" (B 295 and B 788). 
28 Susan Haack 'Reflections on Relativism", in Philosophical Perspectives 11: Metaphysics ed James Tomberlin, Ridgeview Press (forthcoming). Her distinctions between weak and strong mind-(in)dependence, though more complex than the traditional dualism are not quite the same as Kant's. Like Austin, however, I believe that although traditional dualism needs to be rejected, it cannot be adequately replaced with just a three-, four-, or five-fold classification. Experience is more complex than such limited classifications allow. 